\title{
First lipid residue analysis of Early Neolithic pottery from Swifterbant (the Netherlands, ca. 4300-4000 BC)
}

\author{
Özge Demirci $^{1,2} \cdot$ Alexandre Lucquin $^{2} \cdot$ Oliver E. Craig $^{2} \cdot$ Daan C.M. Raemaekers $^{1}$
}

Received: 3 December 2019 / Accepted: 5 April 2020 / Published online: 26 April 2020

(C) The Author(s) 2020

\begin{abstract}
This paper focuses on the functional analysis of Swifterbant pottery from North-western Europe (ca. 4300-4000 BC) through lipid residue analysis. The main aim is to understand the role of pottery in terms of its relation to hunter-fisher-gatherer lifestyle, and the change in available food resources brought about by the arrival of domesticated animal and plant products. We conducted lipid residue analysis of 62 samples from three Swifterbant sites S2, S3 and S4. A combined approach using both GC-MS and GC-C-IRMS of residues absorbed into the ceramic was employed to identify their context. Our results demonstrate that Swifterbant ceramics were used exclusively for processing aquatic resources. We also found no evidence of inter-site variation in the use of pottery or variation based on both typological and technological features of the pottery. We found no evidence for any domesticated resources despite their presence in the faunal and botanical assemblages.
\end{abstract}

Keywords NW Europe $\cdot$ Hunter-fisher-gatherers $\cdot$ Early pottery use $\cdot$ Lipid residue analysis $\cdot$ Swifterbant culture

\section{Introduction}

In many parts of Europe, the transition to farming and the start of pottery production occurred at the same time and both innovations are often considered to be part of a 'Neolithic package' (Barker 2006; Gronenborn 2007; Bailey and Spikins 2008). In contrast, in the western Baltic, so-called Ertebølle pottery was present much earlier than farming and appears to be a forager innovation perhaps derived from contact with ceramic using hunter-gatherers based in the eastern Baltic. The Dutch wetlands also witnessed a somewhat different socio-economic trajectory. Here, pottery production was invented or adopted by hunter-gatherers from ca. $5000 \mathrm{cal} \mathrm{BC}$, but domesticated animals, particularly domesticated cattle, and cereals do not appear in the sequence until ca. 4700 and

Electronic supplementary material The online version of this article (https://doi.org/10.1007/s12520-020-01062-w) contains supplementary material, which is available to authorized users.

Özge Demirci

odemirci@palaeome.org

1 Groningen Institute of Archaeology, Poststraat 6, 9712 ER Groningen, the Netherlands

2 BioArch, Department of Archaeology, University of York, York YO10 5YW, UK
4300 cal BC, respectively (Raemaekers 1999, 2003; Louwe Kooijmans 2003). These groups are commonly termed the 'Swifterbant culture' due to their distinctive material culture, with sites often located in wetlands, between the Scheldt valley (Belgium) and Lake Dümmer (Lower Saxony, Germany) (Raemaekers 1999; Amkreutz 2013). Unlike most other parts of Europe, the adoption of farming in this region did not necessarily lead to large-scale changes in material culture or economic practices. A major economic transition is seen only later, with the introduction of TRB (Trichterbecherkultur) pottery, at ca. 4000 cal BC (ten Anscher 2012; Raemaekers 2012) Here, we investigate the relationship between economic practices and material culture by undertaking the first lipid residue analysis of Swifterbant ceramics to determine their use. A key question is whether Swifterbant ceramics were associated with domesticated animal and plant foods once these became available or whether culinary practices remained essentially unchanged and continued to reflect the hunter-fisher-gatherer economy.

Our initial research focuses on three contemporaneous sites (S2, S3 and S4) in a small area of the Netherlands known as Swifterbant, the type site for the Swifterbant culture, dating from between 4300 and $4000 \mathrm{cal} \mathrm{BC}$. By this time, cereals and domestic animals had become established in the region and had been incorporated into a broader, pre-existing economy based on fishing, hunting and gathering (leading to a so-called 
Fig. 1 Map showing the location of the Swifterbant cluster sites along the freshwater creek system (Devriendt 2014, Fig. 2), overlain on a modern map. Insert map showing the location of the Netherlands in relation to Northern Europe and the location of the Swifterbant cluster within the Netherlands

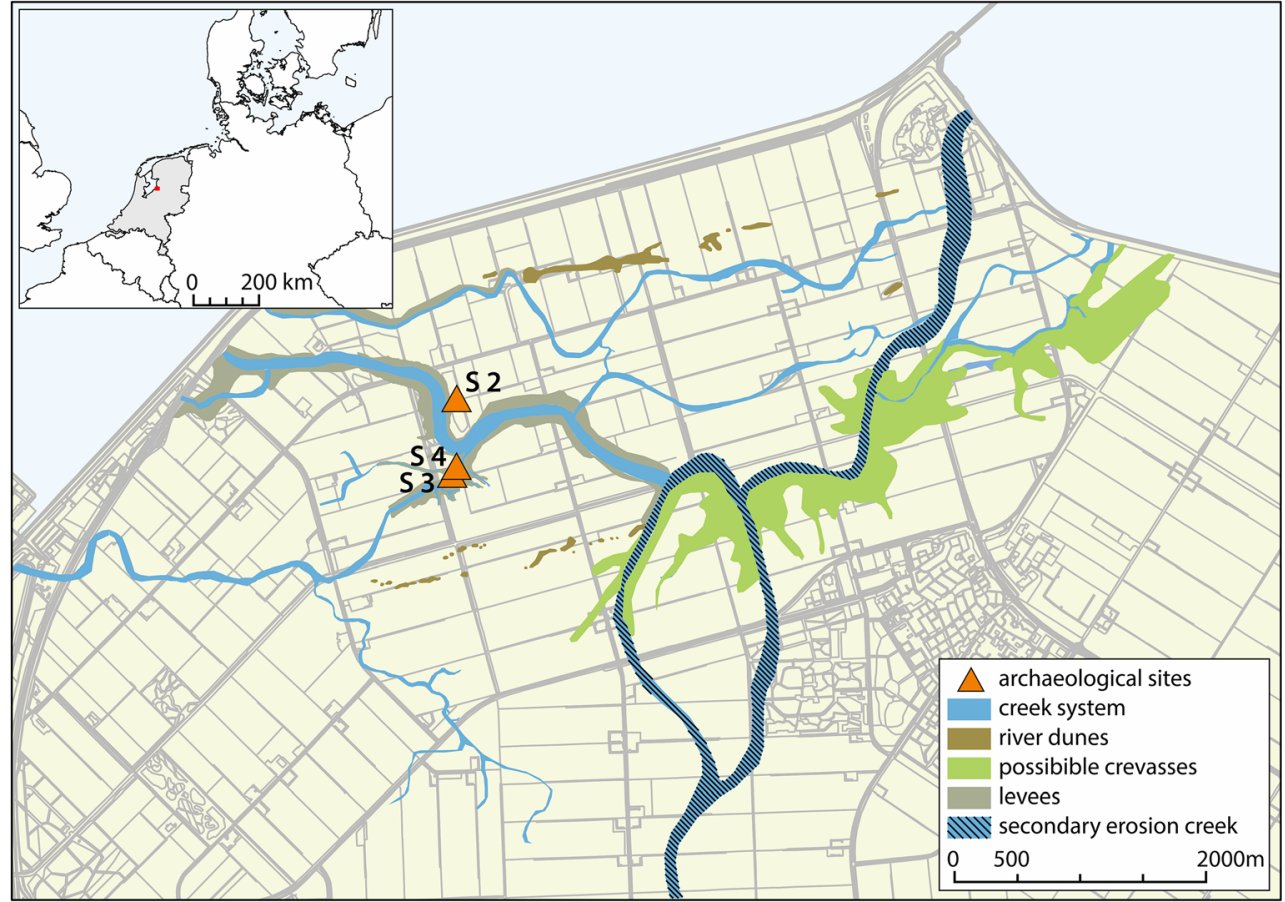

'extended broad spectrum economy') (cf. Louwe Kooijmans 1993). As well as investigating the role of pottery in these forager-farmer societies, this study also offers an opportunity to examine inter-site variation in pottery given the different domestic (S3 and S4) and funerary/ritual (S2) functions that have been proposed for these sites (Devriendt 2014: 220). Lipid residue analysis on Swifterbant pottery is also relevant to the broader debate regarding the transition to farming and the role of ceramics therein; a debate that in Northern Europe is dominated by the Ertebølle culture. From its inception in the 1970s, the Swifterbant culture has been considered a western branch of the Northern European Ertebølle culture (De Roever 1979), an interpretation that still finds an audience (cf. De Roever 2004; Rowley-Conwy 2013). A competing interpretation is that its emergence was unrelated to the Ertebølle culture (Raemaekers 1997; Andersen 2010; ten Anscher 2012), whereas this discussion has until now been based primarily on the technology and typology of the ceramics, the functional analysis provided here will add new fuel to this fire.

\section{The archaeological sites}

The sites of the Swifterbant cluster (Fig. 1) are located in Oostelijk Flevoland, the Netherlands. Oostelijk Flevoland is a large polder, a reclaimed floor of a lake, the Ijsselmeer. The sites were discovered when the ditches between the agricultural plots were dug and are part of a covered and wellpreserved prehistoric landscape which consists of a Neolithic creek system and adjacent sand ridges (occupied during the
Mesolithic and Neolithic). Swifterbant sites S2, S3 and S4 are located on the banks of the Neolithic creek system. S2 $\left(52^{\circ}\right.$, $35^{\prime} 3.0^{\prime \prime} \mathrm{N}, 5^{\circ}, 34^{\prime} 54.5^{\prime \prime} \mathrm{E}$ ) is located along the main Neolithic creek, while the adjacent $\mathrm{S} 3\left(52^{\circ}, 34^{\prime} 44.8^{\prime \prime} \mathrm{N}, 5^{\circ}, 34^{\prime} 56.8^{\prime \prime} \mathrm{E}\right)$ and $\mathrm{S} 4\left(52^{\circ}, 34^{\prime} 46.5^{\prime \prime} \mathrm{N}, 4^{\circ}, 34^{\prime} 57.9^{\prime \prime} \mathrm{E}\right)^{1}$, are located along a side branch, $600 \mathrm{~m}$ south of S2 (Devriendt 2014) (Fig. 1). Several ${ }^{14} \mathrm{C}$ dates from the sites confirms that they were occupied ca. 4300-4000 cal BC (Peeters 2007; Devriendt 2013). The pottery from these sites was extensively studied by De Roever $(1979,2004)$. The archaeological remains indicate the exploitation of both domestic animals, such as pig, cattle and sheep/goat, and game animals, such as beaver and otter. The game animals were hunted for their fur and their meat (Zeiler 1997a). The faunal analysis indicates that pig bones, wild and/ or domesticated, dominate the assemblage (Zeiler 1997a). In terms of fish remains, the sites provide clear evidence for both anadromous (sturgeon, grey mullet and eel) and freshwater (pike, perch and catfish) species (Brinkhuizen 1976; Clason 1978). In addition, archaeobotanical analyses indicated the presence of two types of cereals (naked six-row barley [Hordeum vulgare] and hulled emmer wheat [Triticum turgidum ssp. dicoccum]) and several different wild plant species, such as hazelnut, hawthorn, rose-hip, wild apple and

\footnotetext{
${ }^{1}$ The DMS coordinates mentioned in the text correspond to the location of the archaeological sites. The degree of reliability is $1 \mathrm{~m}$ for all three sites. These coordinates were generated by Erwin Bolhuis (Groningen Institute of Archaeology) based on the information available online on the Dutch Ministry of Education, Culture and Science, National monument register page (for S2, https://monumentenregister.cultureelerfgoed.nl/monumenten/532464; for S3 and S4 https://monumentenregister.cultureelerfgoed.nl/monumenten/ 532465).
} 
blackberry (van Zeist and Palfenier-Vegter 1981; Cappers and Raemaekers 2008).

\section{Materials and methods}

\section{Sample selection}

All three Swifterbant sites mentioned in this paper, S2, S3 and $\mathrm{S} 4$, are identified as unstratified midden deposits with no clear contextual information (Huisman and Raemaekers 2014). Therefore, sherds with different typological and technological features were sampled to make the collection as representative as possible. A selection of 62 sherds (S2, $n=14$; S3, $n=19$; and $\mathrm{S} 4, n=29$ ), all representing individual ceramic vessels, were sampled for lipid residue analysis.

During the process of selecting samples, each fragment was studied from the perspective of form, size, decoration, rim diameter and wall thickness (Online Resource 1). The samples were also analysed under the microscope in order to get a clear understanding of the temper (Online Resource 1). Based on the information collected, the sample set consists of 14 base fragments with either pointed or rounded base, 28 rim fragments and 20 body fragments. The average wall thickness for the pottery is $10 \mathrm{~mm}$ for all three sites. Of the 28 rim fragments, 4 did not provide rim diameter information due to their small size. For the remainder, the rim diameter varied between 20 and $30 \mathrm{~cm}$ with an average of $25 \mathrm{~cm}$ although there are 5 samples smaller than $20 \mathrm{~cm}$ and 3 samples greater than $30 \mathrm{~cm}$ with examples of each appearing at all three sites. Although one of the rim fragments from S2 has more prominent decoration than is usual, overall decoration appears to be uncommon, and where present, simple and matching with the general description of Swifterbant pottery. The base fragments and body sherds show no decoration, with the exception of five body fragments that are decorated with nail impressions (four from S4 and one from S2). In contrast, rim fragments do show decorative patterns mainly on the top of the rim and/or just below the rim, both interior and exterior as well as around the neck again both interior and exterior. The decoration on the top of the rim is a series of spatula or nail impressions, while those below the rim or on the neck area seems to consist of a series of shallow impressions and occasionally, fingertip impressions, which circle the vessel (Fig. 2).

In terms of temper, our samples fit into the general scheme of Swifterbant pottery (Raemaekers and de Roever 2010). The majority of sherds from S3 $(n=14$, out of 19) and S4 $(n=26$, out of 29) indicate plant material together with mica, grit and sand (Online Resource 1). The sherds from S2, in contrast, show an even distribution between plant material $(n=7)$ and grit $(n=7)$ as the most abundant temper. Like S3 and S4, S2 also shows the presence of mica and sand as other tempers. The analysis of the temper does not indicate any correlations with wall thickness or decoration as it was suggested in a previous study on Swifterbant pottery (cf. Raemaekers et al. 2013). The fabric is extremely coarse with no deliberate surface treatment other than occasional hand smoothing. The hand smoothing is more visible on the S2 sherds than it is on the $\mathrm{S} 3$ and $\mathrm{S} 4$ sherds.

\section{Acidified sulphuric acid extraction extraction of lipids}

Ceramic was drilled from the interior portion of each vessel $(n=62)$ and analysed using the established standard protocol, one-step methanol/sulphuric acid extraction (Craig et al. 2013; Correa-Ascencio and Evershed 2014; Papakosta et al. 2015). The outer surface $(\sim 0-1 \mathrm{~mm})$ of the sampling area was first removed, using a Dremel drill, to reduce the external contamination to a bare minimum. Then, the sherds were drilled to a depth of up to $5 \mathrm{~mm}$ on the interior surface to produce ca. two grams of pottery powder. An internal standard (alkane C34, $10 \mu \mathrm{L}$ ) was added to a subsample of powdered sherd (ca. $1 \mathrm{~g}$ ) followed by $4 \mathrm{~mL}$ methanol. The suspended solution was sonicated for $15 \mathrm{~min}$, then acidified with concentrated sulphuric acid $(800 \mu \mathrm{l})$ and heated for $4 \mathrm{~h}$ at $70{ }^{\circ} \mathrm{C}$. Lipids were sequentially extracted with $n$-hexane $(2 \mathrm{~mL} \times 3)$. The extracts were combined and dried under nitrogen at $35^{\circ} \mathrm{C}$. Finally, an additional internal standard ( $n$-hexatriacontane, $10 \mu \mathrm{g}$ ) was added to each sample prior to their analysis by gas chromatography-mass spectrometry (GC-MS) and gas chromatography-combustion isotope ratio mass spectrometry (GC-C-IRMS) in order to obtain molecular and carbon singlecompound isotope results. To control for any contamination introduced during the sample preparation, a negative control, containing no ceramic powder, was prepared and analysed with each sample batch.

\section{Gas chromatography-mass spectrometry (GC-MS)}

GC-MS analysis was carried out on an Agilent 7890A series GC attached to an Agilent 5975C Inert XL mass-selective detector. A splitless injector was used and maintained at $300{ }^{\circ} \mathrm{C}$. The column was inserted into the ion source of the mass spectrometry directly. Helium was used as the carrier gas, with a constant flow rate at $3 \mathrm{~mL} / \mathrm{min}$. The ionisation energy was $70 \mathrm{eV}$, and spectra were obtained by scanning between $m / z 50$ and 800 . Samples $(n=62)$ were analysed by using an Agilent DB-5ms (5\%phenyl) methylpolysiloxane column $(30 \mathrm{~m} \times 0.25 \mathrm{~mm} \times 0.25 \mu \mathrm{m})$. The temperature was set to $50{ }^{\circ} \mathrm{C}$ for $2 \mathrm{~min}$. This was followed by a rise of $10^{\circ} \mathrm{C}$ per minute up to $350{ }^{\circ} \mathrm{C}$. The temperature was then held at $350{ }^{\circ} \mathrm{C}$ for $15 \mathrm{~min}$. Compounds were identified by comparing them with the library of mass spectral data and published data.

All samples $(n=62)$ were also analysed by using a DB$23 \mathrm{~ms}$ (50\%-cyanopropyl)-methylpolysiloxane column $(60 \mathrm{~m} \times 0.25 \mathrm{~mm} \times 0.25 \mu \mathrm{m})$ in simulation (SIM) mode to 
Fig. 2 Illustrations of selected sherds from Swifterbant S2, S3 and S4 (scale 1:3)
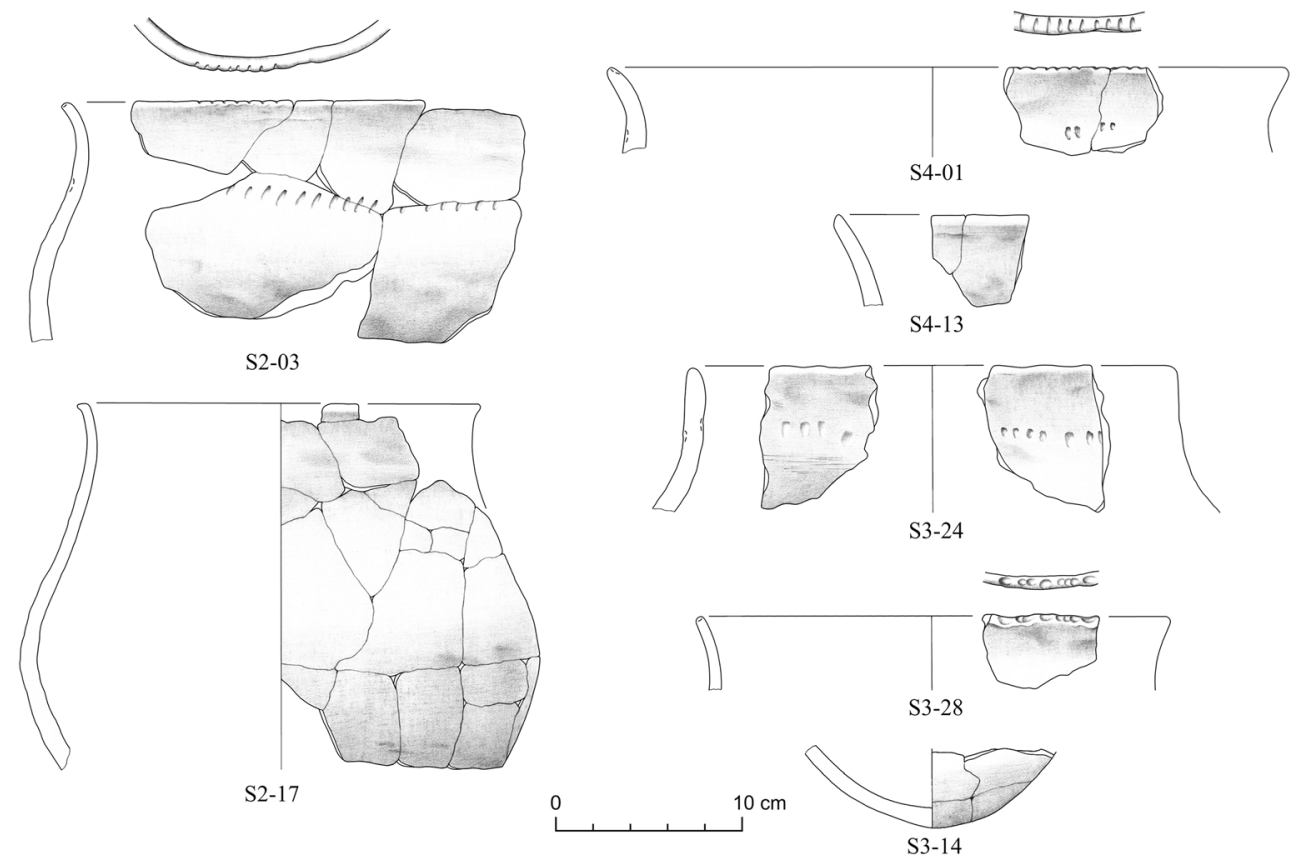

increase the sensitivity for the identification of isoprenoid fatty acids and $\omega$-(o-alkylphenyl) alkanoic acids (APAAs), which can be used to characterise aquatic foods (Cramp et al. 2014; Admiraal et al. 2018). The temperature was set to $50{ }^{\circ} \mathrm{C}$ for $2 \mathrm{~min}$. This was followed by a rise of $4{ }^{\circ} \mathrm{C}$ per minute up to $140^{\circ} \mathrm{C}$, then $0.5^{\circ} \mathrm{C}$ per minute up to $160^{\circ} \mathrm{C}$ and then $20^{\circ} \mathrm{C}$ per minute up to $250^{\circ} \mathrm{C}$. The temperature was then held at $250^{\circ} \mathrm{C}$ for $10 \mathrm{~min}$. Scanning then proceeded with the first group of ions $(\mathrm{m} / \mathrm{z} 74,87,213,270)$, equivalent to $4,8,12$ trimethyltridecanoic acid (TMTD) fragmentation; the second group of ions $(\mathrm{m} / \mathrm{z} 74,88,101,312)$, equivalent to pristanic acid; the third group of ions ( $\mathrm{m} / \mathrm{z} 74,101,171,326)$, equivalent to phytanic acid; and the fourth group of ions $(\mathrm{m} / \mathrm{z} 74$, $105,262,290,318,346)$, equivalent to $\omega$-(o-alkylphenyl) alkanoic acids of carbon length $\mathrm{C} 16$ and $\mathrm{C} 22$. Helium was used as the carrier gas with a constant flow rate at $2.4 \mathrm{~mL} /$ $\mathrm{min}$. Ion $\mathrm{m} / \mathrm{z} 101$ was used to check the relative abundance of two diastereomers of phytanic acids. Quantifications for the peak measurements were calculated by the integration tool on the Agilent ChemStation enhanced data analysis software.

\section{Gas chromatography-combustion isotope ratio mass spectrometry (GC-C-IRMS)}

Forty-two samples which had lipid concentration over $5 \mu \mathrm{g} \mathrm{g}^{-1}$ were analysed by GC-C-IRMS in duplicates based on the existing protocol (Craig et al. 2012), in order to measure stable carbon isotope values of two fatty acid methyl esters, methyl palmitate $\left(\mathrm{C}_{16: 0}\right)$ and methyl stearate $\left(\mathrm{C}_{18: 0}\right)$. Samples were analysed by using Delta $\mathrm{V}$ Advantage isotope ratio mass spectrometer (Thermo Fisher, Bremen, Germany) linked to a Trace Ultra gas chromatograph (Thermo Fisher) with a GC Isolink II interface $(\mathrm{Cu} / \mathrm{Ni}$ combustion reactor held at $1000{ }^{\circ} \mathrm{C}$; Thermo Fisher). All samples were diluted with hexane. Then $1 \mu \mathrm{L}$ of each sample was injected into DB5ms fused-silica column $(60 \mathrm{~m} \times 0.25 \mathrm{~mm} \times 0.25 \mu \mathrm{m}$; J\&W Scientific). The temperature was fixed at $50{ }^{\circ} \mathrm{C}$ for $0.5 \mathrm{~min}$. This was followed by a rise by $25^{\circ} \mathrm{C}$ per minute to $175^{\circ} \mathrm{C}$, then by $8{ }^{\circ} \mathrm{C}$ per minute up to $325^{\circ} \mathrm{C}$. The temperature was then held at $325^{\circ} \mathrm{C}$ for $20 \mathrm{~min}$. Ultrahigh-purity-grade helium was used as the carrier gas with a constant flow rate at $2 \mathrm{~mL} /$ min. Eluted products were ionized in the mass spectrometer by electron ionization and the ion intensities of $\mathrm{m} / \mathrm{z} 44,45$ and 46 were recorded for automatic computation of ${ }^{13} \mathrm{C} /{ }^{12} \mathrm{C}$ ratio of each peak in the extracts (Heron et al. 2015). Isodat software (version 3.0; Thermo Fisher) was used for the computation, based on the comparison with a standard reference gas $\left(\mathrm{CO}_{2}\right)$ with known isotopic composition that was repeatedly measured. The results of the analyses were recorded in $\%$ o relative to an international standard, Vienna Pee Dee belemnite (VPDB).

$\mathrm{N}$-alkanoic acid ester standards of known isotopic composition (Indiana standard F8-3) were used to determine the instrument accuracy. The mean \pm standard deviation (SD) values of these $n$-alkanoic acid ester standards were -29.60 $\pm 0.21 \%$ ond $-23.02 \pm 0.29 \%$ or the methyl ester of $\mathrm{C}_{16: 0}$ (reported mean value vs. VPDB $-29.90 \pm 0.03 \%$ ) and $\mathrm{C}_{18: 0}$ (reported mean value vs. VPDB $-23.24 \pm 0.01 \%$ ), respectively. Precision was determined on a laboratory standard mixture injected regularly between samples (28 measurements). 
The mean \pm SD values of $n$-alkanoic acid esters were -31.65 $\pm 0.27 \%$ o for the methyl ester of $\mathrm{C}_{16: 0}$ and $-26.01 \pm 0.26 \%$ ofor the methyl ester of $\mathrm{C}_{18: 0}$. Each sample was measured in replicate (average SD is $0.07 \%$ or for $\mathrm{C}_{16: 0}$ and $0.13 \%$ o for $\mathrm{C}_{18: 0}$ ). Values were also corrected subsequent to analysis to account for the methylation of the carboxyl group that occurs during acid extraction. Corrections were based on comparisons with a standard mixture of $\mathrm{C}_{16: 0}$ and $\mathrm{C}_{18: 0}$ fatty acids of known isotopic composition processed in each batch under identical conditions.

\section{Results and interpretations}

\section{Results of molecular analysis (GC-MS)}

Based on the molecular analysis of the samples, $98 \%$ of the samples yielded sufficient lipids required for interpretation (i.e. $>5 \mu \mathrm{g} \mathrm{g}^{-1}$ ) (Evershed 2008; Craig et al. 2013) with an average of $243 \mu \mathrm{g} \mathrm{g}^{-1}$ (ranging from 3 to $6186 \mu \mathrm{g} \mathrm{g}^{-1}$ ). The variation between ranges of lipid preservation exists in all three sites. Samples with lipid yields lower than $5 \mu \mathrm{g} \mathrm{g}^{-1}$ were not analysed by GC-C-IRMS.

In general, the molecular analysis results indicate a high abundance of saturated palmitic $\left(\mathrm{C}_{16: 0}\right)$ and stearic $\left(\mathrm{C}_{18: 0}\right)$ acids in all the samples together with the carbon range changing from $\mathrm{C}_{12}$ to $\mathrm{C}_{28}$. The palmitic/stearic acid ratios ( $\mathrm{P} / \mathrm{S}$ ratios) of all the samples are listed Online Resource 1. Although palmitic $\left(\mathrm{C}_{16: 0}\right)$ and stearic $\left(\mathrm{C}_{18: 0}\right)$ acids are present in both animal and plant sources, stearic acid is generally found in higher concentration in terrestrial animals than aquatic and plant food sources (Craig et al. 2007; Papakosta et al. 2015). Higher relative amounts of palmitic acid $\left(\mathrm{C}_{16: 0}\right)(\mathrm{P} / \mathrm{S}$ ratios $>$ 1) in almost all the Swifterbant samples suggest that these vessels were used for processing aquatic food resources or plant products rather than terrestrial animal products.

Forty-five of all the samples yielded unsaturated fatty acids ranging between $\mathrm{C}_{16: 1}$ and $\mathrm{C}_{22: 1}$. Only five samples indicated presence of dicarboxylic acids all with carbon chain length nine. Based on the experimental study, dicarboxylic acids ranging between $\mathrm{C}_{8}$ and $\mathrm{C}_{11}$ are formed during the heating of aquatic oils (Evershed et al. 2008). A total of eleven samples contained cholesterol indicating presence of animal fats (Evershed 1993). Although cholesterol may be derived from vessel use, it may also be a contaminant arising during handling of the sherds.

Thirty-one of 62 samples contained $\omega$-(o-alkylphenyl) alkanoic acids (APAAs), with carbon atoms ranging from 18 to 22 , and isoprenoid fatty acids, including TMTD $(4,8,12$ trimethyltridecanoic acid), pristanic acid $(2,6,10,14$ tetramethylpentadecanoic acid) and phytanic acid $(3,7,11,15$ tetramethylhexadecanoic acid). These data meet the established criteria for identifying aquatic lipids in the ancient pottery (Evershed et al. 2008; Hansel et al. 2004; Craig et al. 2007; Cramp and Evershed 2014; Heron et al. 2015); Heron et al. 2015). In addition, APAAs are formed by heating of polyunsaturated fatty acids obtained in aquatic organisms; therefore, must have been derived from primary use of the vessels (Hansel et al. 2004; Craig et al. 2007). Two samples yielded only $\mathrm{C}_{18}, \mathrm{C}_{20}$ and/or $\mathrm{C}_{22}$ APAAs with no isoprenoid acids. They are also considered an evidence of aquatic products because $C_{20}$ and $C_{22}$ APAAs are formed from long-chain polyunsaturated fatty acids $\left(\mathrm{C}_{20}\right.$ and $\left.\mathrm{C}_{22}\right)$ which are not present in terrestrial animal fats (Hansel et al. 2004). Another four samples yielded partial aquatic biomarkers containing $\mathrm{C}_{18}$ APAA and isoprenoid acids (Online Resource 1).

None of the samples yielded plant derived lipids (e.g. phytosterols) (Online Resource 1). Interestingly, scanning electron microscope (SEM) analysis on the carbonized surface deposits (foodcrust) collected from pottery from the S3 site has indicated the processing plant material (Raemaekers et al. 2013), albeit relating to different sherds than those analysed here. SEM analysis on S3 vessels identified plant fragments such as chaff and leaf tissues of emmer (Triticum dicoccum) as they survived the food processing and cooking stages. The SEM results indicated that plant products were cooked with other food sources, as one vessel also contained fish scale remains (Raemaekers et al. 2013). Given the evidence of the use of the emmer in the foodcrusts from S3 vessels, the absence of plant biomarkers in our results may come as a surprise. As plant foods have low lipid content, they may be overprinted by other animal fats and may therefore be very difficult to detect through lipid residue analysis (Colonese et al. 2017; Hammann and Cramp 2018). This opens up a new discussion on whether Swifterbant vessels are used for mixing freshwater fish and plant food sources. Resolving this requires further combined lipid residue and SEM analyses.

\section{Isotopic identification of individual fatty acids (GC-C-IRMS)}

Forty-two samples with sufficient fatty acid yields (< $5 \mu \mathrm{g} \mathrm{g}^{-1}$ ) were analysed by GC-C-IRMS in order to determine the carbon stable isotopes values of their $\mathrm{C}_{16}$ and $\mathrm{C}_{18}$ fatty acids. The data from the samples are listed in Dataset-1 (Online Resource 1) and plotted in Fig. 3a against reference ranges of authentic modern animal fats collected from the Western Baltic. In Fig. $3 \mathrm{~b}$, the $\delta^{13} \mathrm{C}$ values of the $\mathrm{C}_{16: 0}$ acid are plotted against $\Delta^{13} \mathrm{C}$ values (difference between $\delta^{13} \mathrm{C}_{18: 0}$ and $\delta^{13} \mathrm{C}_{16: 0}$ ) which allows us discrimination of ruminant adipose, non-ruminant and dairy fats (Craig et al. 2012, 2013; Cramp et al. 2014).

In general, the carbon isotope values from all three sites provided $\delta^{13} \mathrm{C}$ values of $\mathrm{C}_{16: 0}$ and $\mathrm{C}_{18: 0}$ fatty acids consistent with freshwater organisms (Fig. 3a), confirming the results of the molecular analysis. The majority of the 


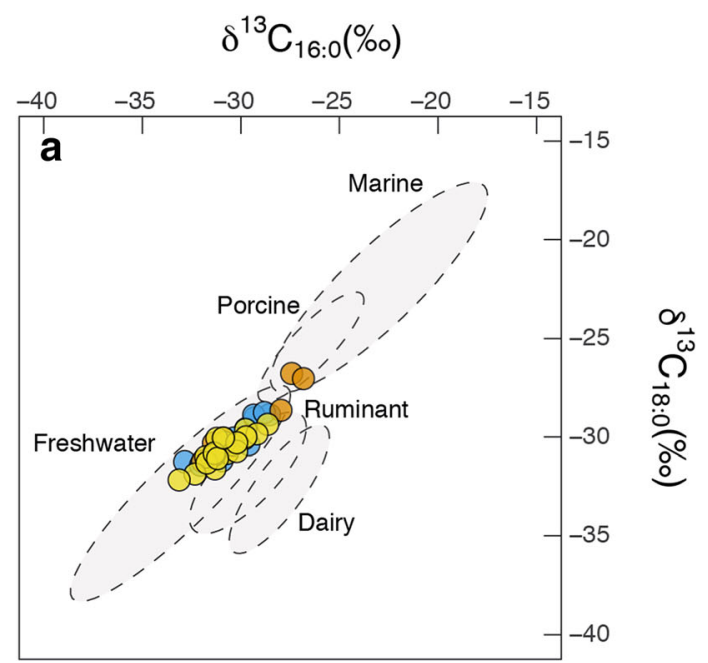

Site $\bigcirc \mathrm{S2} \bigcirc \mathrm{S3} \quad \bigcirc \mathrm{s} 4$

Fig. 3 Stable carbon isotope measurements of $\mathrm{C}_{16: 0}$ and $\mathrm{C}_{18: 0}$ fatty acids obtained from ceramic matrices of Swifterbant pottery by site. a Plot of $\delta^{13} \mathrm{C}_{16: 0}$ and $\delta^{13} \mathrm{C}_{18: 0}$ values against ranges of authentic reference fats and

samples which plot in this area (21 out of 35) have fully aquatic biomarkers (Online Resource 1), verifying that they were used for processing aquatic products, mainly freshwater fish.

Two samples (S305 and S328) from S3 plot within the range of modern porcine and marine fats (Fig. 3a). Wild and possibly domesticated pig (S. scrofa/Sus domesticus) are the most abundant terrestrial species at S3 (Zeiler 1997a, p.99). There is no evidence for marine mammals at the Swifterbant sites, and there are only two marine fish species, thin-lipped grey mullet (Mugil capito Cuvier) and flounder (Platichths flesus L.) representing a very small percentage (1\% of in situ material, $n=611 ; 0.4 \%$ of sieved material, $n=3825$ ) of the total fauna material found in S3 (Brinkhuizen 1976; Clason 1978). In addition, both of these marine species are known to swim far upstream into freshwater environments (Brinkhuizen 1976; Clason 1978; Zeiler 1997a). Sturgeon (Acipenser sturio L.), an anadromous fish that migrates from the sea to the rivers in springtime to spawn and would be expected to have a marine carbon isotope signature, is also present in Swifterbant sites (Brinkhuizen 1976; Clason and Brinkhuizen 1978) but again at a very small percentage $(<1 \%)$ (Zeiler 1997a). Based on these, it is clear that marine species were not a major part of the diet at Swifterbant S2, S3 and S4 and that there was no deliberate exploitation of the coastal areas for fishing or sea mammal hunting. Thus, it is unlikely that these ceramic vessels were used to process marine resources. As only one of these two samples contained fully aquatic biomarkers (S328) (Online Resource 1), a more plausible hypothesis is that this residue contains a mixture of freshwater and porcine derived lipids.

None of the samples had $\Delta^{13} \mathrm{C}$ values lower than $-1 \%$, the value that is an indicator for ruminant fat (Evershed et al.

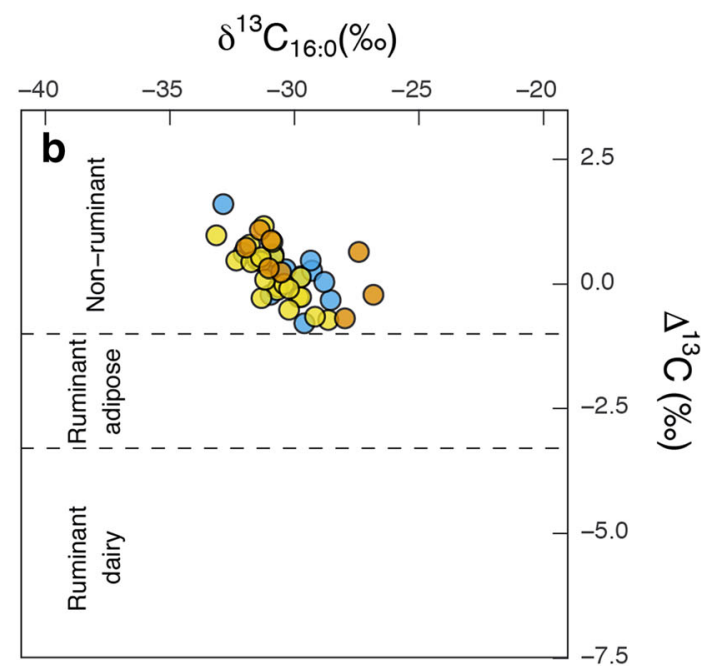

oils. Ellipses indicate the $95 \%$ confidence interval. b Plot of $\Delta^{13} \mathrm{C}$ $\left(\delta^{13} \mathrm{C}_{18: 0}\right.$ and $\left.\delta^{13} \mathrm{C}_{16: 0}\right)$ values against $\delta^{13} \mathrm{C}_{16: 0}$ values obtained from ceramic matrices

2002; Copley et al. 2003; Craig et al. 2012) (Fig. 3b; Online Resource 1). It is known that ruminant animals, especially domesticated cattle, were present in all three Swifterbant sites (Raemaekers 1999), and they must have been part of the diet. However, based on the molecular and isotopic results of the samples, it is likely that ruminant products were processed and cooked in different ways rather than using pottery. Finally, the isotope values clearly indicate that there are no dairy products in any of the Swifterbant pots analysed, as the $\Delta^{13} \mathrm{C}$ values of the samples are all higher than $-3.3 \%$ (Fig. $3 b$ ). It should be noted that even a minor contribution of ruminant fat would be expected to be detected given there is a strong bias against aquatic oils when mixed with ruminant fats due to the differences fatty acid concentration between these products (Cramp et al. 2019).

\section{Discussion}

\section{Relationship between form and function}

The starting point for this analysis was the pilot study that was carried out on 32 vessels from Swifterbant S3 (Raemaekers et al. 2013). The combination of scanning electron microscope (SEM) and organic residue analysis using direct temperatureresolved mass spectrometry (DTMS), a form of in-source pyrolysis mass spectrometry, distinguished two functional groups. The first group of grit-tempered, thin-walled and relatively well-made pots, contained emmer wheat based on the SEM analysis, whereas the second group of plant-tempered, thick-walled and relatively poorly made pots showed no such evidence (Raemaekers et al. 2013). The lipid residue data presented here seemingly contradicts this previous study. 
Although we tested different pots, we see no variation in vessel function by typological or technological features (Online Resource 1). According to the lipid residue evidence, Swifterbant pottery was used for processing freshwater fish regardless of vessel form, size, decoration or temper. In reconciling these studies, we need to take into account that the functional differences proposed in the Raemaekers et al. (2013) pilot study were revealed only by SEM analysis rather than by DTMS and that processing of fish and cereals either together or sequentially could provide an explanation. Our current study underlines the relevance of combining lipid residue analysis and SEM analysis for the functional interpretation of ceramics, and it clearly outlines an avenue for future research.

\section{Comparison between pottery use and other evidence for subsistence strategies}

Based on analysis of the zooarchaeological and archaeobotanical remains, the subsistence economy at all three sites appears to have relied on a mixture of aquatic and terrestrial animal and plant resource, pointing to an economic pattern based on hunting-fishing-gathering, horticultural-scale cereal cultivation and small-scale animal husbandry (Cappers and Raemaekers 2008; Huisman et al. 2009; Huisman and Raemaekers 2014). Other dietary evidence such as stable isotope analysis of human bones from two of the Swifterbant sites (6 human teeth from S2 and 4 human teeth from S3) indicates a high intake of aquatic foodstuffs together with a definite terrestrial input (Smits and van der Plicht 2009; Smits et al. 2010: Table 1). Evidence of butchery found on S3 pig/ wild boar and cattle bones also supports this evidence (Zeiler 1997b). We conclude that while there is a bias against the identification of plant foods through lipid residue analysis, carcass fats from pigs and cattle should be readily identifiable, and therefore, pigs and cattle must have been processed and cooked in different ways. Significantly, we found no evidence for dairy products which are readily identifiable in prehistoric pottery from other sites in Northern and other areas of Europe (Craig et al. 2011; Cramp et al. 2019; Heron et al. 2015). The use of pottery vessels was instead focused on processing freshwater fish which were selected from a much wider range of animal resources available.

\section{Inter-site variation}

There are important differences between the three sites. Most striking is the difference in the presence of burials. S2 has nine burials, whereas S3 has no burials and S4 has only a single inhumation (Raemaekers et al. 2009). Another difference is the presence of postholes. Site S3 yielded many postholes which are interpreted to be the remnants of a rebuilt house (c. $4.5 \times 8 \mathrm{~m}$ ). Site $\mathrm{S} 4$ yielded only few postholes and these could not be attributed to a structure (Geuverink 2020). Site S2 produced only one line of postholes, and these did not correspond to a house plan (De Roever 2004). In addition, Devriendt proposes that S3 and S4 had a domestic or residential function on the basis of the dominance of scrapers in the flint tool assemblage, whereas S2 has many more retouched blades (Devriendt 2014). Some of these blades must have been imported as finished products, because they are larger than the flint cores found. One hypothesis was that S3 and S4 were domestic sites, where one might expect a full range of foods to have been cooked in the ceramic vessels, whereas S2 was a special-function site, where vessels use was primarily related to the burial ritual. It was not possible to support this hypothesis on the basis of our analysis. The lipid residue analysis does not indicate any inter-site functional variation in the Swifterbant pottery.

\section{Interregional perspective: Swifterbant vs Ertebølle}

While both Swifterbant (5000-4000 cal BC) and Ertebølle (4800-4000 cal BC) were contemporary, the relationship between these groups is the subject of on-going discussion, notably based on similarities and differences in ceramic vessels (De Roever 1979; Raemaekers 1997; De Roever 2004; Andersen 2010; Louwe Kooijmans 2010; ten Anscher 2012; Rowley-Conwy 2013). Along with pointed-based pottery present in both cultural groups, the Ertebølle pottery repertoire also includes elongated bowls (blubber lamps) used for illumination (Heron et al. 2013) which are completely absent in Swifterbant assemblages. Later comparisons have focused on other material cultures, such as lithic tools as well as subsistence practices, which have highlighted greater differences between these two cultures (Deckers 1982; Raemaekers 1997; Raemaekers 1998; Stilborg 1999; Andersen 2010; Ballin 2014). An important difference is that compared with the Swifterbant, there is very little evidence for domesticated plants and animals at any Ertebølle sites, and the occasional find is interpreted to be the result of contact with nearby farmers (Krause-Kyora et al. 2013). With the new data we generated from the lipid residue analysis of Swifterbant S2, S3 and S4 pottery assemblages, we now can contribute to the discussion from the perspective of pottery use.

Lipid residue analyses indicates Late Mesolithic Ertebølle pottery (ca.4600-3950 BC) from both coastal and inland sites had a broad range of functions including processing of aquatic resources, both marine and freshwater (Craig et al. 2007), but also terrestrial animal fats, particularly ruminant fats (Craig et al. 2007; Philippsen et al. 2010; Heron et al. 2013; Philippsen and Meadows 2014; Papakosta et al. 2019). A recent study (Papakosta et al. 2019) shows mixing of aquatic and terrestrial food products in the Ertebølle pots based on their isotope values. Stable isotope analysis of carbonised surface deposits (foodcrust) from inland Ertebølle sites also 
suggests a mixture of freshwater and terrestrial ingredients and is not able to rule out the presence of terrestrial plants (Philippsen et al. 2010; Philippsen and Meadows 2014). Moreover, phytoliths from garlic mustard seed were also found in Ertebølle pottery at Neustadt and Stenø (Saul et al. 2013), although no evidence for cereals in Ertebølle pottery has so far been recorded. The residue analysis undertaken on Ertebølle pottery contrasts with our results from the three Swifterbant sites. Swifterbant pottery, at least based on evidence from these three sites had a more specialised function associated with freshwater fish. We, therefore, conclude that these different cultures did not share the same kind of approach towards the use of pottery, even when sites located in similar wetland environments are compared, e.g. Store Åmose basin and Ringkloster in Denmark (Craig et al. 2011), although most of the Ertebølle lipid residue data are from coastal settlement sites. Unfortunately, comparable Swifterbant coastal settlements are absent due to erosion of the coastal zone preventing a more detailed comparison.

\section{Conclusion}

The first combined molecular and isotopic analysis of lipids provides clear evidence for the processing of freshwater fish at all three studied Swifterbant sites. The homogeneity of the results is striking and shows that variation in size, decoration and temper is not mirrored in the use history of the vessels. Currently we have no evidence for different uses of vessels across the three sites, i.e. between 'domestic sites' (S3 and S4) and the 'ritual site' (S2). The absence of ruminant fats and dairy products in the Swifterbant pottery is quite clear and in sharp contrast to European Neolithic pottery, where these products are readily detected (e.g. Cramp et al. 2019). While it may be that any differences are only manifest in the use of plant foods which are difficult to detect through lipid analysis, it may also be a true reflection of homogeneity in Swifterbant pottery use. This possibility opens up other avenues of research, rethinking the production, exchange and use of pottery and the role pottery played in the expression of social identities and cultural preferences as has been debated previously (Taché and Craig 2015; Robson et al. 2018). Additional analysis of Swifterbant pottery from different sites is clearly needed to contribute to the debate regarding the function of the hunter-gatherer pottery in Northern Europe, nevertheless the data presented here provide a significant advance in our knowledge for this period and region and points to different culinary practices to contemporary hunter-gatherers in adjacent regions.

Acknowledgements We thank Erwin Bolhuis (Groningen Institute of Archaeology) who produced the map for Fig. 1 and Frits Steenhuisen (Arctic Centre, Groningen) for his additional help on it. We also thank
M.A. Los-Weijns (Groningen Institute of Archaeology) for the pottery illustrations in Fig. 2. We thank Helen Talbot and Matthew Von Tersch for their assistance with aspects of laboratory work.

Funding information This project is part of a Marie Sklodowska-Curie European Joint Doctoral Training Program, funded by the European Union's EU Framework program for Research and Innovation Horizon 2020 under the Grant Agreement No. 676154 (ArchSci2020 program).

Open Access This article is licensed under a Creative Commons Attribution 4.0 International License, which permits use, sharing, adaptation, distribution and reproduction in any medium or format, as long as you give appropriate credit to the original author(s) and the source, provide a link to the Creative Commons licence, and indicate if changes were made. The images or other third party material in this article are included in the article's Creative Commons licence, unless indicated otherwise in a credit line to the material. If material is not included in the article's Creative Commons licence and your intended use is not permitted by statutory regulation or exceeds the permitted use, you will need to obtain permission directly from the copyright holder. To view a copy of this licence, visit http://creativecommons.org/licenses/by/4.0/.

\section{References}

Admiraal M, Lucquin A, von Tersch M, Jordan PD, Craig OE (2018) Investigating the function of prehistoric stone bowls and griddle stones in the Aleutian Islands by lipid residue analysis. Quat Res 91(3):1-13

Amkreutz, L. W. S. W. (2013). Persistent traditions: a long-term perspective on communities in the process of Neolithisation in the lower Rhine area (5500-2500 cal BC. Dissertation Leiden University

Andersen, S. H. (2010). The first pottery in South Scandinavia. In B. Vanmontfort, L. Louwe Kooijman, L. Amkreutz, L. Verhart (eds.), Pots, farmers and foragers: how pottery traditions shed a light on social interaction in the earliest Neolithic of the lower Rhine area (pp. 167-176). Leiden University Press

Bailey G, Spikins P (eds) (2008) Mesolithic Europe. Cambridge University Press, Cambridge

Ballin, T. B. (2014). The culture concept and the Ertebølle-Swifterbant dispute a spin-off from the debate between Raemaekers and Stilborg (or: the basic elements of prehistoric territorial studies)

Barker G (2006) The agricultural revolution in prehistory: why did foragers become farmers? Oxford University Press, Oxford

Brinkhuizen, D. C. (1976). Preliminary notes on fish remains from archaeological sites in the Netherlands. Palaeohistoria, 21(0), 83-90

Cappers RTJ, Raemaekers DCM (2008) Cereal cultivation at Swifterbant? Neolithic wetland farming on the North European Plain. Curr Anthropol 49(3):385-402

Clason AT (1978) Worked bone, antler and teeth. A preliminary report (Swifterbant contribution 9). Helinium 18:83-86

Clason AT, Brinkhuizen DC (1978) Swifterbant, mammals, birds, fishes. Preliminary report. Swifterbant contribution 8. Helinium 18:69-82

Colonese AC, Hendy J, Lucquin A, Speller CF, Collins MJ, Carrer F, Gubler R, Kühn M, Fischer R, Craig OE (2017) New criteria for the molecular identification of cereal grains associated with archaeological artefacts. Sci Rep 7(1):6633

Copley MS, Berstan R, Dudd SN, Docherty G, Mukherjee AJ, Straker V, Evershed RP (2003) Direct chemical evidence for widespread dairying in prehistoric Britain. Proc Natl Acad Sci U S A 100(4):1524 1529 
Correa-Ascencio M, Evershed RP (2014) High throughput screening of organic residues in archaeological potsherds using direct acidified methanol extraction. Anal Methods 6(5):1330-1340

Craig OE, Forster M, Andersen SH, Koch E, Crombé P, Milner NJ, Heron CP (2007) Molecular and isotopic demonstration of the aquatic products in northern European prehistoric pottery. Archaeometry 49(1):135-152

Craig OE, Steele VJ, Fischer A, Hartz S, Andersen SH, Donohoe P, Heron CP (2011) Ancient lipids reveal continuity in culinary practices across the transition to agriculture in Northern Europe. Proc Natl Acad Sci U S A 108(44):17910-17915

Craig OE, Allen RB, Thompson A, Stevens RE, Steele VJ, Heron C (2012) Distinguishing wild ruminant lipids by gas chromatography/combustion/isotope ratio mass spectrometry. Rapid Commun Mass Spectrom 26(19):2359-2364

Craig OE, Saul H, Lucquin A, Nishida Y, Taché K, Clarke L, Jordan P (2013) Earliest evidence for the use of pottery. Nature 496(7445): 351-354

Cramp LJE, Evershed RP (2014) Reconstructing aquatic resource exploitation in human prehistory using lipid biomarkers and stable isotopes. In: Holland HD, Turekian KK (eds) Treatise on geochemistry, second edn. Elsevier, Oxford, pp 319-339

Cramp LJE, Evershed RP, Lavento M, Halinen P, Mannermaa K, Oinonen M, Heyd V (2014) Neolithic dairy farming at the extreme of agriculture in Northern Europe. Proc R Soc Lond B Biol Sci 281(1791):20140819

Cramp LJE, Ethier J, Urem-Kotsou D, Bonsall C, Borić D, Boroneanț A, Evershed RP, Perić S, Roffet-Salque M, Whelton HL, Ivanova M (2019) Regional diversity in subsistence among early farmers in Southeast Europe revealed by archaeological organic residues. Proceedings Biological Sciences / The Royal Society 286(1894): 20182347

De Roever JP (1979) The pottery from Swifterbant-Dutch Ertebølle? (Swifterbant contribution 9). Helinium 19:13-39

De Roever, J. P. (2004). Swifterbant aardewerk: Een analyse van de neolithische nederzettingen bij Swifterbant 5e millennium voor Christus. Dissertation, University of Groningen

Deckers PH (1982) Preliminary notes on the neolithic flint material from Swifterbant (Swifterbant contribution 13). Helinium 22:33-39

Devriendt, I. (2014). Swifterbant stones: the Neolithic stone and flint industry at Swifterbant (the Netherlands): from stone typology and flint technology to site function. Dissertation, University of Groningen

Evershed RP (1993) Biomolecular archaeology and lipids. World Archaeol 25(1):74-93

Evershed RP (2008) Organic residue analysis in archaeology: the archaeological biomarker revolution. Archaeometry 50(6):895-924

Evershed RP, Dudd SN, Copley MS, Berstan R, Stott AW, Mottram H, Crossman Z (2002) Chemistry of archaeological animal fats. Acc Chem Res 35(8):660-668

Evershed RP, Copley MS, Dickson L, Hansel FA (2008) Experimental evidence for the processing of marine animal products and other commodities containing polyunsaturated fatty acids in pottery vessels. Archaeometry 50(1):101-113

Geuverink, J. (2020). Features and spatial analysis. In D.C.M. Raemaekers and J.P. de Roever (eds)., Swifterbant S4 (the Netherlands) Occupation and exploitation of a neolithic levee seite (c. 4300-4000 cal. BC). Barkhuis Publishing, p. 98-106

Gronenborn D (2007) Beyond the models: "Neolithisation" in Central Europe. In: Gronenborn D (ed) Going over: the MesolithicNeolithic transition in North-West Europe. British Academy, London, pp 73-98

Hammann S, Cramp LJE (2018) Towards the detection of dietary cereal processing through absorbed lipid biomarkers in archaeological pottery. J Archaeol Sci 93:74-81
Hansel FA, Copley MS, Madureira LAS, Evershed RP (2004) Thermally produced $\omega$-(o-alkyl phenyl) alkanoic acids provide evidence for the processing of marine products in archaeological pottery vessels. Tetrahedron Lett 45(14):2999-3002

Heron C, Andersen S, Fischer A, Glykou A, Hartz S, Saul H, Craig O (2013) Illuminating the Late Mesolithic: residue analysis of "blubber" lamps from Northern Europe. Antiquity 87:178-188

Heron C, Craig OE, Luquin A, Steele VJ, Thompson A, Piličiauskas G (2015) Cooking fish and drinking milk? Patterns in pottery use in the southeastern Baltic, 3300-2400 cal BC. J Archaeol Sci 63:33-43

Huisman DJ, Raemaekers DCM (2014) Systematic cultivation of the Swifterbant wetlands (the Netherlands). Evidence from Neolithic tillage marks (c. 4300-4000 cal. BC). J Archaeol Sci 49:572-584

Huisman DJ, Jongmans AG, Raemaekers DCM (2009) Investigating Neolithic land use in Swifterbant (NL) using micromorphological techniques. Catena 78(3):185-197

Krause-Kyora B, Makarewicz C, Evin A, Flink LG, Dobney K, Larson G, Hartz S, Schreiber S, von Carnap-Bornheim C, von WurmbSchwark N, Nebel A (2013) Use of domesticated pigs by Mesolithic hunter-gatherers in northwestern Europe. Nat Commun $4: 2348$

Louwe Kooijmans LP (1993) Wetland exploitation and upland relations of prehistoric communities in the Netherlands. East Anglian Archaeology 50:71-116

Louwe Kooijmans, L. P. (2003). The Hardinxveld sites in the Rhine/ Meuse Delta, the Netherlands, 5500-4500 cal BC, in: L. Larsson, H. Kindgren, K. Knutsson, D. Loeffler a. Åkerlund (eds): Mesolithic on the move. Papers presented at the sixth international conference on the Mesolithic in Europe, Stockholm 2000. Oxford: oxbow books, pp. 608-624

Louwe Kooijmans LP (2010) The ceramisation of the Low Countries, seen as the result of gender-specific processes of communication. In: Vanmontfort B, Louwe Kooijmans L, Amkreutz L, Verhart L (eds) Pots, farmers and foragers: pottery traditions and social interaction in the earliest Neolithic of the Lower Rhine Area. Leiden University Press, Leiden, pp 27-40

Papakosta V, Smittenberg RH, Gibbs K, Jordan P, Isaksson S (2015) Extraction and derivatization of absorbed lipid residues from very small and very old samples of ceramic potsherds for molecular analysis by gas chromatography-mass spectrometry (GC-MS) and single compound stable carbon isotope analysis by gas chromatography-combustion-isotope ratio mass spectrometry (GC-C-IRMS). Microchem J 123:196-200

Papakosta V, Oras E, Isaksson S (2019) Early pottery use across the Baltic - a comparative lipid residue study on Ertebølle and Narva ceramics from coastal hunter-gatherer sites in southern Scandinavia, northern Germany and Estonia. J Archaeol Sci Rep 24:142-151

Peeters, J. H. M. (2007). Hoge Vaart-A27 in context: towards a model of mesolithic - neolithic land use dynamics as a framework for archaeological heritage management. Amersfoort Rijksdienst voor Archeologie, Cultuurlandschap en Monumenten

Philippsen, B., Meadows, J. (2014), Inland Ertebølle culture: the importance of aquatic resources and the freshwater reservoir effect in radiocarbon dates from pottery food crusts. Internet Archaeology 37

Philippsen B, Kjeldsen H, Hartz S, Paulsen H, Clausen I, Heinemeier J (2010) The hardwater effect in AMS 14C dating of food crusts on pottery. Nuclear instruments \& methods in physics research. Section B, Beam Interactions with Materials and Atoms 268(7): 995-998

Raemaekers DCM (1997) The history of the Ertebølle parallel in Dutch Neolithic studies and the spell of the point-based Pottery 1. Archaeological Dialogues 4(2):220-234

Raemaekers DCM (1998) Ertebølle and Swifterbant: a comparison of attitudes. Anthropologie et Préhistoire 109:155-161

Raemaekers, D. C. M. (1999). The articulation of a "New Neolithic" dissertation Leiden University 
Raemaekers D (2003) Cutting a long story short? The process of neolithization in the Dutch delta re-examined. Antiquity 77(298): 740-748

Raemaekers, D. C. M. (2012). Rethinking Swifterbant S3 ceramic variability. Searching for the transition to TRB before 4000 calBC. In J. Kabaciński, S. Hartz, D. Raemaekers, T. Terberger (eds.), The Dabki Site in Pomerania and the Neolithisation of the North European Lowlands (c. 5000-3000 calBC). Rahden: Verlag Marie Leidorf, pp. 321-334

Raemaekers, D. C. M. and de Roever, J. P. (2010). The Swifterbant pottery tradition (5000-3400 BC). In B. L. L. Vanmontfort, K. L. P. Louwe, L. W. S. W. Amkreutz, \& L. B. M. Verhart (Eds.), Pots, Farmers and Foragers. Pottery traditions and social interaction in the earliest Neolithic of the Lower Rhine Area Leiden University press, pp. 135-149

Raemaekers DCM, Molthof HM, Smits E (2009) The textbook 'dealing with death' from the Neolithic Swifterbant culture (5000-3400 BC), the Netherlands. Berichte Römisch-Germanische Kommission 88: $479-500$

Raemaekers DCM, Kubiak-Martens L, Oudemans TFM (2013) New food in old pots - charred organic residues in early Neolithic ceramic vessels from Swifterbant, the Netherlands (4300-4000 cal BC). Archäologisches Korrespondenzblatt 43(3):315-334

Robson H, Oras E, Hartz S et al (2018) Illuminating the prehistory of northern Europe: organic residue analysis of lamps. In: Lozovskaya O, Vybornov A, Dolbunova E (eds) Subsistence strategies in the stone age, direct and indirect evidence of fishing and gathering. Saint Petersburg, Institute for the History of Material Culture Russian Academy of Science, pp 214-217

Rowley-Conwy P (2013) North of the frontier: early domestic animals in northern Europe. In: Colledge S, Connoly J, Dobney K, Manning K, Shennan S (eds) The origins and spread of domestic animals in Southwest Asia and Europe. Left Coast Press, Walnut Creek, pp 283-312
Saul H, Madella M, Fischer A, Glykou A, Hartz S, Craig OE (2013) Phytoliths in pottery reveal the use of spice in European prehistoric cuisine. PLoS One 8(8):e70583

Smits L, van der Plicht H (2009) Mesolithic and Neolithic human remains in the Netherlands: physical anthropological and stable isotope investigations. Journal of Archaeology in the Low Countries 1(1):55-85

Smits E, Millard RA, Nowell G, Pearson DG (2010) Isotopic investigation of diet and residential mobility in the Neolithic of the lower Rhine Basin. Eur J Archaeol 13(1):5-31

Stilborg O (1999) Dutch Swifterbant and Swedish Ertebølle: a debate on regionality and ceramic analysis. Archaeological Dialogues 6(1): $47-54$

Taché K, Craig OE (2015) Cooperative harvesting of aquatic resources and the beginning of pottery production in North-Eastern North America. Antiquity 89(343):177-190

ten Anscher, T. J. (2012). Leven met de Vecht: Schokland-P14 en de Noordoostpolder in het neolithicum en de bronstijd. Dissertation University of Amsterdam

van Zeist W, Palfenier-Vegter RM (1981) Seeds and fruits from the Swifterbant S3 site. Final Reports on Swifterbant IV. Palaeohistoria 23:105-168

Zeiler JT (1997a) Hunting, fowling and stock-breeding in the Dutch Neolithic. Archaeofauna 6:97-113

Zeiler, J. T. (1997b). Hunting, fowling and stock-breeding at Neolithic sites in the western and central Netherlands dissertation Groningen University

Publisher's note Springer Nature remains neutral with regard to jurisdictional claims in published maps and institutional affiliations. 